\title{
Trends and Prospects of Transformation of the Social Structure of the Russian Scientific Community
}

\author{
Konstantin Viktorovich Vodenko
}

\author{
Svetlana Alexandrovna Tikhonovskova
}

Olga Sergeevna Ivanchenko

\author{
Platov South-Russian State Polytechnic University (NPI) \\ Email: vodenko-kv@rambler.ru; thonovskovas@yandex.ru; Iga.ivanchenko1509@mail.ru
}

Doi:10.5901/mjss.2015.v6n3s6p313

\begin{abstract}
In the article are analyzed theoretical approaches to the definition of the concept "scientific community". The author examines the socio-cultural changes in the social structure of the Russian scientific community. Among them, are identified on the basis of separation of transformation of power structures, material separation, stratification based on involvement in international cooperation. Prospects of development of the scientific community in modern Russian conditions are considered, and ways of overcoming of negative consequences of sociocultural changes in the scientific community are outlined. Sociocultural changes of the Russian scientific community testify to transformational processes in its social structure. The intensive stratification of this social and professional group initiating stratification as in the structure of the scientific power, and allocation in scientific community of the special group - "new Russian scientists" possessing the considerable material and reputation capital, and which is actively involved in the international cooperation results.
\end{abstract}

Keywords: science, society, culture, the scientific community, scientists.

\section{Introduction}

In modern conditions of formation of the information society, the science and high technologies are the effective lever of social and economic development of any state. According to M. Weber, "scientific progress is a part, and besides the primary, that process of intellectualization which happens to us throughout the millennia" Weber M. (1990).

The science increases activity power of those spheres to which delivers to the model of structuring reality and alternative decisions. However the science is, first of all, the people working in the sphere of science. In these conditions, the analysis of scientific community as a collective form of the subject of knowledge and backbone factor of the sociocultural environment of the development of science is of particular importance.

The comparative analysis of activity of scientific communities in a historical and social retrospective of its evolution allowed revealing the following peculiar features, characteristic of it during the different periods of science development.

During the pre-classical period of development of science (Antiquity and the Middle Ages), there is an accumulation of knowledge, development of scientific methodology and rational approaches, rules of a logical reasoning. At this stage the communicative structure as a prototype of scientific community, uniting scientists on the "teacher-pupil" type, (for example, The Platonic Academy), or acting as temporary voluntary communities of scientists in concrete scientific spheres is formed (schools of thought, which develops scientific knowledge constitutes the scientific ethos, being installed on the truth which involves a blessing). Conclusions of the arising and developing scientific knowledge are not demanded yet by society; there is no narrow pragmatism.

\section{Methodological Aspects of Studying}

The classical period (the XVI-XVIII centuries) is characterized by the origin of modern experimental natural sciences, the principles of the scientific technique based on inductive methods of scientific research Vodenko K.V. (2013). Classical science technogenic society develops through paradigm and has the following specifics: expanding communication connection by legitimizing the new challenges and the collective subject; there is a new layer - the scientific community as a collective subject of science with his characteristic ethos ("invisible college" Republic of scientists), there are the first 
association of scientists with state status, issued community of professional scientists; priority development of basic research obtained, the proportion of applied empirical, applied research is still small (Vodenko K.V. \& Tikhonovskova S.A., 2015); communications are implemented through monographs, scientific articles, and so on.

In the first half of the XIX century in strategy of interaction with scientific community and world around prepotent installations are promotion of "pure" science and tactics of "a functional autonomy of science" (according to A. Gouldner) Gouldner A. (2003). Representatives of scientific communities interpret autonomy of science as financial support of independent scientists in the choice.

During the nonclassical period (end of XIX-XX centuries.) the science becomes the dominating form of public consciousness and is made out of a social Institute, there are changes in structure and social functions of the scientific community. Scientific activity becomes a steady sociocultural tradition; the science turns into the body and the tool of a state policy; considerably the role of applied research, their large-scale increases.

The social and professional structure of scientific community (now it already joins scientists and engineers) changes, there is a registration of differentiation of scientific community, its crushing on more and more specialized scientific communities on a subject sign, liberalization of system of scientific communities develops, there is a change in their stratification structure. The new social group of "intellectuals" (the western equivalent) - "intellectuals" are gradually formed, and the international integration is built. The main positions of ideology based on traditions of the scientific community are made out (ethos sciences).

In the post-nonclassical period of development of science (the end of the XX-XXI centuries) the subject field of knowledge when the science goes beyond the framework extends and gets into other areas, scientific communications of scientific community on the basis of domination of design, problem-oriented nature of scientific activity, new forms of communication of science and practice, development of computer technologies as much as possible extend, nationalization, politicization and commercialization of science develop. There is a high-quality change in a way of implementation of scientific communication - it gains the virtual character which is washing away national and geographical boundaries of activity of scientific community more and more, the structure of the relations in scientific community changes, its social responsibility is increased. At this stage, the scientific community acts as the tool of a state policy, the state infrastructure of science is made out. Before the scientist, there is a dilemma of a moral choice connected with the acute contradiction between professional and social responsibility.

So, as a social phenomenon the scientific community passed a rather long period of formation in development, with each new stage complicating and differentiating the characteristics.

As for the research of scientific community in the context of a theoretic-methodological discourse, attempt to define it began only in the middle of the XX century. Now, depending on specifics of a subject field of research are offered various definitions of scientific community. So, in the philosophy of the scientific community it brings together scientists, belonging usually to a single scientific discipline working in a scientific field, adhering to the general theoretical foundations, principles and methods for solving research problems.

Within science philosophy "scientific community", first of all, understand set of the professional scientists organized according to specifics of a scientific profession (Encyclopedia of epistemology and philosophy of science, 2009) as a phenomenon. The sociology considers "scientific community" as a set of the individuals or collectives connected by an exchange of activities for production, accumulation or use of knowledge and maintaining the steady interpersonal and intergroup relations Jeri D. \& Jeri John (1999).

We will use as working definition the definition accepted in sociology of science according to which "the scientific community" is understood as the social community of people arising and functioning in the course of specific socially necessary type of work - professional scientific activity Babosov, E.M. \& Mamedov, A.K. (2011).

Discussion and development of ideas of specifics of scientific community happened in the context of a fierce debate between representatives of various scientific directions about development of scientific knowledge (first of all, positivism, neopositivism and post-positivism). Within a discourse "Big Four" of theorists, whose works were allocated, performances, and scientific polemic created the main approaches to the theory of scientific knowledge in general, and to a phenomenon perspective "scientific community" in particular: K. Popper, M. Polanyi, I. Lakatos, P. Feyerabend.

Semantic value of the term "scientific community" as essential element of science, "The personal knowledge" was for the first time offered and proved by M. Polanyi in work Polanyi M. (1995) where the author criticizes the concept of evolutionary epistemology of K. Popper. The author proposed and established the qualitatively new epistemological theory, "the concept of implicit knowledge" (tacit knowledge), which main postulate - a priority of a human factor in science. The concept Polanyi approves inevitability of inclusion of a subjective factor (personal estimates, valuable reference points, etc.) in society. The social factor of discovery, synthesis subjective and objective according to the author, is the reason of a scientific collectivism as a way of an assessment of the validity of opening, criterion of scientific 
character.

An important merit of M. Polanyi is that he characterized the scientific community as the system of difficult social and communicative communications allowing the subject of science to receive an assessment and recognition. On the other hand, the structural composition of system of scientific communities acts at Polanyi as the mechanism of selforganization of scientists thanks to which the subjective confidence in the validity and reliability arising at the level of personal perception through criteria of a scientific assessment and mutually recognition by scientific community, comes to new level and forms scientific conglomerates in the plane of scientific community.

Almost simultaneously with the M. Polanyi issues of the scientific community involved in Kuhn, whose work formed the basis of modern approaches to the study and understanding of this phenomenon. Coming, as well as M. Polanyi, in a polemic with Karl Popper, Kuhn in his work "The Structure of Scientific Revolutions" suggested and substantiated the original social model of the development of science. T. Kuhn explains with a change of paradigms regularity of the development of science, causes the nature and nature of scientific revolutions. However, the fundamental concept of $T$. Kuhn's theory is not the paradigm, but "scientific community". The author shares these concepts, but does not oppose them, and gives logical justification of their complementarity. As a result, T. Kuhn draws a conclusion that the development of science, in fact, can be presented as processes of acceptance and denial of fundamental scientific theories (paradigms) by the scientific community. Acceptance of the new paradigm satisfying scientific community causes requirement of formation of new samples, means of statement and the solution of problems within "normal science" that, finally, forms a new type of scientific thinking. T. Kuhn proves a paradigm as a basis for self-identification and reproduction of the most scientific community. On the other hand, according to the author, the paradigm acts as substantial, more a social and psychological kernel round which the concrete scientific community unites. Thus, the acceptance or denial of the paradigm leads to the existence of competition among the "paradigm - community" that is the basis of self-organization of the scientific community and the development of science.

The importance of the concept of T. Kuhn is that within the research "paradigm-community" environments, he for the first time offers the structured model of scientific community in which scientists form various professionally directed groups. The scientific community Kuhn - free and open source, based on the rational wisdom of each. On the other hand, the freedom and openness of the limited "intelligence community", recognizing the rationality of its members, making the scholar is more dependent on the forms and principles of thinking of the scientific community.

Other scientists, whose work on the problems of the scientific community have a unique place in the framework of discourse was I. Lakatos. Speaking from the position of positivism and arguing with T. Kuhn, I. Lakatos, however, disputed, and some positions of Karl Popper, whose disciple and follower, he was. Moreover, though the phenomenon of the scientific community is not crucial for I. Lakatos, for his research hypothesis, there is the especially obvious importance of the theory and related research program for the scientist activity. Beyond his teaching, he is simply not able to work. The main source of the development of science is not the interaction of theory and empirical evidence, and competition research programs in a better description and explanation of the observed phenomena and, most importantly, the prediction of new facts.

It is possible to distinguish P. Feyerabend from T. Kuhn's followers, the author revolutionary to the "anarchist theory of knowledge" based on ideas of theoretic-methodological pluralism. According to P. Feyerabend's concept, the scientific community represents a conglomerate of authors of autonomous theories. Each of representatives of scientific community has the right (and in fact has to) to deny the existing methods of scientific knowledge and formulating the new methods, violating the conventional rules, thereby to lay the foundation of scientific revolutions. A basis of the evolution of science and existence of the scientific community, P. Feyerabend as well as T. Kuhn, saw in the competition ("incommensurability") of theories/paradigms. Protecting T. Kuhn's thesis about the noncumulative type of scientific revolutions and competition of paradigms, P. Feyerabend supported the autonomy of science and scientific community from policy, religions, different ideologies, and dogmas. The person considered the scientist has to have the opportunity for self-determination and a freedom of choice. In fact, Paul Feyerabend replaced the epistemological arguments "scientific community" is a separate individual, which gave a result of the so-called "epistemological anarchism" Porus V.N. (1997).

It is impossible to disregard and research of the founder of the concept of a steady and universal ethos R. Merton, which work issued in our opinion two key directions in understanding of the phenomenon "scientific community". First in the article "Science and Democratic Social Structure" were offered them a set of a system of behavioral standards, obligatory for the scientific community: universalism, communism, disinterest, organized skepticism.

Moral and value imperatives (CUDOS) Robert Merton called debate in the scientific community, which has become central to the idea that the imperatives of Merton refers rather to the ideal model for research than real work. Although Merton concept and sharply criticized by many scientists (W. Hirsch, S. Barnes, R. Dolby, W. Hagstrom, R. Boguslaw, I. 
Mitrof, M. Malki, B. Latour and S. Vulgare, S. Fuller et al.), however, it has managed to consolidate the scientific community in view of the normative regulative science for many years.

Within scientific polemic about a problem of an ethos of science R. Merton's contention in 1994 was developed by J. Ziman, who proved qualitatively new system of valuable norms, characteristic for modern (post-academic) science. The list of norms offered by Ziman represents the modified Merton's CUDOS - PLACE system: Proprietary, Local, Authoritarian, Commissioned and Expert work Ziman J. (1994). Let's note what exactly it methodologically fixed process of an institutionalization of science in general and scientific community as social group, that allowed to define a framework of the social organization of scientific community in the conditions of submission to the state and commercialization of science.

The second conceptual thesis of R. Merton, which formed a basis for modern approaches in researches of a phenomenon «scientific community», is so-called "Matthew Effect" Merton R.K. (1993). Based on quotes from the Gospel of Matthew ("For whoever has, to him shall be given, and abundance: but whosoever hath not, from him shall be taken and what is" the Gospel of Matthew 13:12), Merton justifies the postulate of significance, according to which the famous scientist influences the recognition of his scientific results, regardless of their significance. R.Merton main merit is that his research formed the applied research methods of the scientific community - the so-called empiricism R. Merton.

Characteristic evidence of Merton "Matthew Effect" began studies W. Hagstrom and N. Storer, who focused on the study of the phenomenon of the scientific community in the context of the analysis of internal motivation and organization of independent work of the scientist. In particular, by W. Hagstrom made attempt to reveal motivators of behavior of the scientist, his aspiration to gain recognition of scientific community, and N. Storer placed emphasis on behavioural aspects of members of scientific community, motivator and mechanisms of social management of scientists. Also as well as W. Hagstrom, N. Storer carries out differentiation of scientific community, based on "division of science into disciplines", but, unlike the last, at N. Storer as the basis and the main condition of the internal and external communicative channels of "a scientific profession" influencing behavior of scientists act valuable criteria. Realization of need for development of the conventional criteria by means of which value of a scientific contribution for all area of scientific knowledge is estimated, does, according to N. Storer, "a scientific profession" institute with institutional structures and signs, characteristic for it. But in this case development of science, from the point of view of the sociologist, is represented as continuous process of differentiation of its values and norms in which as the main dividing force the scientific discipline acts.

Let's also note Peter M. Haas's concept, defined scientific community "as a network or set of the professionals working in the sphere of specialized knowledge" Peter M. Haas (1992). Here already the accent is put on communicative networks in the scientific environment.

In domestic sociology of science of work of such scientists as E.Z. Mirskaya, N. Yakhiyel, M. A. Rozov, E.M. Babosov, A.K. Mamedov considerably added concepts of foreign sociologists, considering a problem of scientific community in relation to the Russian reality. In particular, in E.M. Babosov and A.K. Mamedov's work "Science sociology" the sophisticated analysis of scientific community as structural component of social institute of science is given, including structural and stratification characteristics, elements of an informative basis of activity are revealed, differentiation of functions and typology of scientific community is offered.

Let's ask a question: what features of the scientific community in modern Russia? Apparently, the present model of the Russian science is transitional, so, and not efficient design. In other words, it is a model in which the part of structures and mechanisms is introduced almost without changes from command system; other their part is quite adequate to the principles of market economy. If not to give any quality standards to these or those phenomena and processes, the present model of the Russian science can be described as follows.

On specific number occupied in science, Russia takes the 9th place in the world after Finland and Iceland today. Unfortunately, on rates of reduction of number of researchers we advance even the extreme forecast stated by experts of the Organization for Economic Cooperation and Development (OECD) though it both was represented at that time improbable and met sharply negative reaction of scientific community.

A particular concern is caused by social tension in the environment of the scientific and technical intellectuals. Deep apathy, protest actions, mass departure abroad are the indicative reaction of scientists to the happening destructive processes in our science.

At the same time, the principle of openness and an inclusiveness of our science in world though here, and there are difficulties are realized. Existence at each of the parties to such interaction of own traditions and history of development complicates their cooperation. Lack of a uniform welfare platform, necessary knowledge of system of realization of scientific and technological development in the international market, and also administrative and managerial mechanisms of integration of the Russian scientific groups into the international transfer of knowledge led to a number of consequences, negative for Russia: on the one hand, to move by the Russian researchers of knowledge and 
technologies to unequal conditions for them, and on the other hand, to formation at the western colleagues of negative image of the Russian scientist as "inexperienced" partner.

Let's note for the positive moment disappearance of ideological barriers in domestic science. In legislative base on ensuring development of the Russian science, more than ten laws (in particular, patent) in an intellectual field of activity that initiated development of small innovative business are adopted. For development of fundamental science, the nondepartmental funds (The Russian humanitarian scientific fund, the Russian fund of basic research, the Russian scientific fund) operating on principles of equality of applicant, competition and independence of examination were created.

Now the organizational structure of science starts changing slowly. Considerably the sizes of the research organizations (RO) decrease, there were new sectors of non-state science and small innovative business existing both in the form of the innovative and technological centers and science and technology parks and in the form of independent structures. The financial and information infrastructure of these sectors is created. The state and private innovative and investment funds work; the association of venture investment started working.

In the conditions of openness and the competition, there is a noticeable differentiation of potential of RO; however, the remaining regionalism and a paternalism disturb processes of natural selection and closing of inefficient $\mathrm{RO}$.

The privatization of the branch scientific and technical organizations which is carried out hasty and with mistakes, nevertheless, opened a way to the creation of "intra-firm" science, normal for a market economy. There were many examples of successfully working scientific and technical structures, practically entirely financed by the industrial enterprises.

On the other hand, very considerable part of the academic sector of science, part of branch RO, including many state scientific centers, almost did not change the principles of the organization, management, and financing. All this conducts only to degradation of their scientific potential, lag from world leaders, to the unwillingness of young scientists to work in such organizations.

The demographic structure of scientific community shows a dangerous tendency to increase of a share of advanced age. However, over the past few years interest of youth in natural science and technical colleges that give a sure hope for a revival of the Russian science grew considerably.

Rather sharp is a management problem in science, which, according to experts, is inadequate to new economic realities. Especially it is noticeable at the science micro level - management of the scientific and technical organizations.

In this regard, we see the main problem of our science not so much in insufficiency of the budgetary financing (in the next years its essential increase is hardly possible), how many that also present budget funds are very inefficiently used. In addition, this consequence of not finished reform of the scientific and technical sphere. Here inadequately big and "friable" network of the scientific organizations, outdated funding mechanisms and archaic system of the organization of scientific activity where traditional departmental institutes of the Soviet type still dominate have to become the main objects of reforming, in our opinion. In other words, the considerable part of a way of creation of a new model of functioning of the Russian Science us is still not taken place.

Especially it is necessary to allocate a problem of a social status of scientists in public structure, which is directly connected, with the general crisis state of science as a social institute.

At the characteristic of scientific community first of all it should be noted that it worries new, occurring on nonconventional signs, and very intensive stratification covering the level of the income, ways and results of adaptation to domestic option of market economy, a psychological state, ideological and political orientations, etc. As a result of this process solidity of the scientific community that gives us the grounds to speak about transformational processes in the social structure of the scientific community is lost.

Considering socio-structural changes of the scientific community, it is necessary to point to the multidimensionality of their manifestations. It is possible to allocate, at least, two directions of changes. First, stratification of scientific community finds expression in stratification of structures of the power that allows to speak about complicated nature of this process proceeding both on individual, and at the institutional level, covering both certain scientists, and scientific institutes.

The second important direction of socio-structural changes of modern scientific community is stratification on the level of the income. No wonder that the low level of compensation as the main factor of dissatisfaction with the work was always called by most of the scientists. Besides, lack of opportunity to conduct the full research also strengthened feeling of disappointment at the increasing number of scientists. At the same time against the general deterioration of indicators of a condition of the scientific community, some data testify to relative improvement of the financial position of a number of researchers. It is connected, first of all, with the advent of selective (grant) financing of separate projects, any combining jobs that significantly expanded in the sphere of science and strengthened differentiation in the scientific environment. However it must be kept in mind, that in this case growth of an indicator of grant security of researchers is 
caused not only the objective development of this type of financing, but also counting system of results selection. Also, an increase in a share of owners of foreign grants is explained by the last though the quantity of foreign grants in the Russian academic science did not increase in reality, and significantly decreased. Apparently, for the expired period interest of foreign scientific funds in our science considerably went down, and the quantity of foreign money in the Russian research was sensitively reduced Ivanchenko O.S. (2014).

So, stratification of the modern Russian community of scientists conducts to allocation in it a unique group that in recent years became even more noticeable, having extended and having strengthened the positions. What it for a group? Let's agree with the researcher A.V. Yurevich, that it is possible to call his "new Russian scientists," having allocated as backbone signs the following Yurevich A.V. \& Tsapenko I.P. (2010):

- a variety of sources of the income, work at the same time in different places;

- corresponding property base;

- worthy knowledge, at least, one foreign language and its regular use;

- high level of a demand, regular obtaining offers of work, publications, etc. from different places and deficiency of free time;

- modern level of technical training;

- receiving grants of domestic and foreign scientific funds, cooperation with the last also as the expert;

- The combination of scientific activity with an inclusiveness in the system of the higher education, teaching in serious higher education institution;

- regular trips abroad and popularity in world science;

- performances in mass media and cooperation with various public organizations - as the expert, the analyst, etc.

One more stratification sign in scientific community is the involvement into the international cooperation, which is determined by publications in foreign editions, to reports at the international conferences, to participation in joint research, receiving grants from the western funds and organizations, use of operational means of scientific communications, etc.

On these indicators, each scientist can be carried to one of five groups $(A-E)$ in the international cooperation. So, scientific groups $A$ are scientific elite - leaders of the international interaction and the most productive figures of domestic science; the group B are very active specialists in the international cooperation that professional achievements in the native environment did not meet expectations; group $C$ - self-assured professional performers without whom scientific research are impossible; the group $D$ unites the scientists with very high scientific potential but who are very poorly included in the international interactions and the most unsatisfied; the group $\mathrm{E}$ which not so have the international contacts shows, as a rule, low professional indicators in domestic science and as it is strange, the most positive estimates of own activity.

It should be noted that these groups of a different profile and different level of elitism indicate "thin structure" of research community and allow to leave from idea of "the average scientist" (no more productive, than idea of "the average income") and the amorphous mass of researchers characterized by average indicators. This position is shown in social well-being of scientists. For example, on average on selection for scientists, the number of the scientists satisfied with the scientific activity makes $25 \%$, are not satisfied $-60 \%$, and found it difficult to answer $-15 \%$. However, in different groups of scientists of mood considerably differed Yurevich A.V. \& Tsapenko I.P. (2010).

So, socio-structural changes in scientific community are caused by pragmatical approach to science, brought to that society does not provide inflow of new forces to this sphere, badly stimulates their work, does not create necessary priorities for creativity. It is necessary to use as much as possible such incentives of scientific search as its fair assessment from scientific community, public recognition, creation of conditions for promotion of talented scientists, democratization of management of science, expansion of discussions, updating of channels of scientific communications. In "science studies' literature are drawn three scenarios of this future:

- the scenario I - "optimistic" - a revival of the Russian science, bringing expenses to the level accepted for its development;

- the scenario II - "pessimistic" - continuation of the destruction of domestic science up to its full disintegration;

- the scenario III - "moderated" - preservation of present situation with its variables that weak improvement, some deterioration, preservation "states live, death".

In the modern developed conditions revival of the Russian science through an education system as in recent years education endures all main signs of revival is represented to the most probable: annually expenses for education, number of students, total of higher education institutions, competition at entrance examinations, etc. increase. Development system of the higher education is capable to become the catalyst for positive changes in science.

Integration of the Russian scientists into the European transfer of knowledge belongs to one of the perspective 
options of development and preservation of domestic scientific and technological potential. The prospect of development of the scientific community is carried out by the scientific community to community scientific technologically; the last is focused on research so-called "social technologies", which is particular forms of the management organization. Besides, scientific and technological communities investigate the potential and tendencies of technical development, various spheres and forms of use of equipment.

Summarizing, we will draw some conclusions. The comparative analysis of scientific communities at different stages of historical development of society revealed peculiar features of their scientific activity: a discursive and contemplation in the period of antiquity and authoritarianism of thinking with theological rationality during a Middle Ages era (traditional society); the scientific community in classical science of industrial society is defined by a paradigm; as feature of scientific community in nonclassical science its interpretive character acts; for scientific community in information society virtuality is characteristic.

\section{Conclusion}

The accent in the solution of a question of self-organization of scientific community in scientific researches is put on a miscellaneous: if for I. Lakatos and S. Toulmin prevalence of rational judgments of scientists is decisive, M. Polanyi and J. Holton give a priority to specific psychological features of the scientist while P. Feyerabend insists on socially determined nature of development of scientific knowledge. In a post-positivistic paradigm of scientific knowledge search of new balance between these factors is characteristic, and also attempts to enter new factors are made: personal belief, evolutionary development, sociocultural environment. At the same time, the increasing popularity is gained by the theories underlining the economic nature of scientific activity.

Sociocultural changes of the Russian scientific community testify to transformational processes in its social structure. The intensive stratification of this social and professional group initiating stratification as in the structure of the scientific power, and allocation in scientific community of the special group - "new Russian scientists" possessing the considerable material and reputation capital, and which is actively involved in the international cooperation results.

\section{References}

Weber, M. (1990) Selected works. M.: Progress.

Vodenko, K.V. (2013) The socio-cultural legitimation of scientific knowledge in the religious and philosophical thought of the Renaissance and the Reformation // The humanities of South of Russia. № 3. pp. 74-82

Gouldner, A. (2003) A crisis of Western sociology. St. Petersburg: Nauka.

Encyclopedia of epistemology and philosophy of science (2009). M.: "Canon +".

Jeri, D. \& Jeri John (1999) Big explanatory sociological dictionary. Vol. 1. M.: Veche, ACT.

Babosov, E.M. \& Mamedov A.K. (2011) Sociology of Science. M.: Publisher of IBA.

Polanyi, M. (1995) Personal knowledge. On the way to the post-critical philosophy. M.: Progress.

Porus, V.N. (1997) The dispute about scientific rationality // Philosophy of Science. Vol. 3

Ziman, J. (1994) Prometheus bond. Science in a dynamic steady state. Cambridge: Cambr. Univ. Press.

Merton, R.K. (1993) Matthew Effect in Science: Accumulation of benefits and the symbolism of intellectual property // Almanac THESIS. World Rights. № 3.

Haas, P. M. (1992) Introduction: Epistemic communities and international policy coordination // International Organization, Vol. 46, No. 1, Knowledge, Power, and International Policy Coordination. Winter, 1992. pp. 1-35.

Ivanchenko, O.S. (2014) The scientific community as a social actor in the modernization of modern Russia: problems and solutions /I Modern problems of science and education. № 3.

Yurevich, A.V. \& Tsapenko, I.P. (2010) Science in the modern Russian society. M.: Institute of Psychology RAS.

Vodenko, K.V. \& Tikhonovskova, S.A. (2015) The Influence of Religious Values on the Development and Functioning of Economic Institutions // Mediterranean Journal of Social Sciences. Vol. 6, No. 3, May 2015. Supplement 4. pp. 45-51. 
